Published in final edited form as:

Curr Protoc Immunol. 2001 May ; CHAPTER: Unit-7.25. doi:10.1002/0471142735.im0725s01.

\title{
Isolation of Tissue Mast Cells
}

\author{
Marianna Kulka* and Dean D. Metcalfe ${ }^{* *}$ \\ "National Research Council Canada, Institute for Nutrisciences and Health, 550 University \\ Avenue, Charlottetown, Prince Edward Island, Canada, C1A 4P3 \\ ${ }^{* *}$ Laboratory of Allergic Diseases, National Institute of Allergy and Infectious Diseases, National \\ Institutes of Health, 10 Center Drive MSC 1881, Bethesda, MD 20892-1881, USA
}

\section{Mini Abstract}

Located primarily in tissues, mast cells are one of the principle effector cells in allergic inflammation. Mast cells derive from mononuclear precursor cells which undergo their final phase of differentiation in the tissues. Mast cells express a unique set of proteases and display functional diversity depending on the tissue in which they differentiate - a phenomenon often referred to as mast cell heterogeneity. Enzymatic digestion and density centrifugation have often been used to isolate human mast cells from tissues such as lung and skin that have frequentlyresulted in cells with low viability and purity. Here, we describe a protocol that combines gentle enzymatic digestion with positive selection techniques to isolate reasonably viable and substantially enriched preparations of tissue mast cells.

\section{Key Terms}

mast cells; human mast cells; lung; skin; fluorescent activated cell sorting (FACS); magnetic bead columns

This unit describes methods for isolating and enriching mast cells from human skin or lung tissue. The first basic protocol describes the isolation of mast cells from human skin and has been successfully used to isolate cells from breast tissue and human foreskin. The second basic protocol details techniques for the isolation of mast cells from human lung tissue. The number and purity of mast cells obtained from the protocols described in this unit are sufficient for investigating mast cell receptor-induced mediator release, receptor-dependent chemotactic responses, proliferation and survival. Genetic characterization using quantitative PCR or microarray analysis requires highly pure (>99\%) mast cells and thus requires further enrichment using fluorescent activated cells sorting or magnetic bead column isolations (also described here).

NOTE: Unless indicated, all tissue culture supplies and pipettes are sterile disposable plasticware obtained from the following suppliers: Falcon (tubes, cell strainers, tissue culture dishes and plates), Sarstedt (tissue culture flasks, bottle top filters) and Nunc (tissue culture flasks).

Address correspondence to: Marianna Kulka, PhD. National Research Council Canada, Institute for Nutrisciences and Health, 550 University Avenue, Charlottetown, Prince Edward Island, Canada, C1A 4P3. 


\section{Basic Protocol 1 \\ Isolation of skin mast cells}

Mast cells are tissue-resident cells that are implicated in allergic inflammatory diseases such as asthma, atopic dermatitis, allergic rhinitis and idiopathic urticaria. Upon crosslinking of their high affinity IgE receptors (FceRI), mast cells release preformed mediators (such as histamine, proteases tryptase, chymase and TNF) and newly synthesized mediators (such as prostaglandins, leukotrienes, cytokines, chemokines, and growth factors). It is widely believed that skin mast cells are involved in a number of processes including the innate immune response to infectious organisms. In normal skin, mast cells, which are primarily of the tryptase/chymase subtype, occur in the greatest density in the superficial dermal zone(Church and Clough, 1999). Like all other types of mast cells, human skin mast cells bind IgE with high affinity to specific FceRI receptors, but unlike those from lung or intestine, skin mast cells also express the C5a receptor (CD88) and degranulate in response to substance P, VIP, and compound 48/80(Okayama et al., 1992). Some of the difficulties in studying mast cell biology are due to the difficulty in obtaining human mast cell lines that adequately mimic skin mast cells. The HMC- 1 cell line does not generally express functional FceRI receptors, does not contain and is not stem cell factor dependent(Nilsson et al., 1994). Therefore, it is often necessary to isolate skin mast cells from fresh human tissue. Skin mast cells are typically isolated by mechanically and proteolytically digesting skin tissue. However, mast cells obtained from adult tissue using this method may be of limited purity ( $>50 \%)$, suspect viability and in a semi-activated state. The following protocols combine gentle enzymatic digestion with positive selection for Fc\&RI to optimally enrich skin mast cell populations.

CAUTION: When working with human tissue, cells or infectious agents, biosafety practices should be followed.

Materials-Human mast cell culture medium:

$500 \mathrm{ml}$ RPMI containing L-glutamine and sodium biocarbonate (Invitrogen)

Fetal Bovine Serum (FBS; Invitrogen)

Penicillin $(100 \mathrm{U} / \mathrm{ml}) /$ Streptomycin $(100 \mu \mathrm{g} / \mathrm{ml})$ solution (Invitrogen)

1 M HEPES solution (StemCell Technologies)

Combine $500 \mathrm{ml}$ of RPMI, $50 \mathrm{ml}$ FBS, $10 \mathrm{ml}$ of penicillin/streptomycin solution and 10 $\mathrm{ml}$ of HEPES solution and filter sterilize through a $0.2 \mu \mathrm{m}$ bottle-top filter. Adjust $\mathrm{pH}$ to 7.6.

Note: Supplemented RPMI medium can be stored for 3-4 weeks at $4{ }^{\circ} \mathrm{C}$ in the dark.

Phosphate buffered saline (PBS; Invitrogen)

Ammonium chloride $\left(\mathrm{NH}_{4} \mathrm{Cl}\right.$; StemCell Technologies)

Tris (Sigma-Aldrich)

$\mathrm{NaOH}$ solution (10 N; Sigma-Aldrich)

$15 \mathrm{ml}$ conical graduated polypropylene centrifuge tubes (Falcon)

$50 \mathrm{ml}$ conical graduated polypropylene centrifuge tubes (Falcon)

$100 \times 15-$ mm petri dishes (Falcon)

70 micron cell strainer (Falcon) 
Bovine Pancreatic Deoxyribonuclease I (Sigma-Aldrich)

Hyaluronidase (Sigma-Aldrich)

Collagenase (Sigma-Aldrich)

Tweezers, scissors, and scalpels, kept in sterile beaker with $70 \%$ ethanol

Percoll@ (Sigma-Aldrich)

Fresh skin segments stored in sterile PBS at $4^{\circ} \mathrm{C}$ or on ice

Note: Tissue segments that have been stored at $4^{\circ} \mathrm{C}$ longer than $24 \mathrm{hr}$ should not be used. Tissue samples should never be frozen.

Tabletop centrifuge

Anti-FceRI- APC (eBioscience)

Mouse IgG-APC (eBioscience)

Anti-CD117-PE (BD Pharmingen)

Mouse $\mathrm{IgG}_{1}$-PE (BD Pharmingen)

\section{Prepare solutions}

1 Lysis buffer

$1.37 \mathrm{~g} \mathrm{NH} 4 \mathrm{Cl}$

$0.515 \mathrm{~g}$ Tris

$250 \mathrm{~mL}$ ddH2O $\mathrm{pH}$ to 7.2

3 Protease solution

$0.2 \mathrm{mg} / \mathrm{mL}$ collagenase

$0.1 \mathrm{mg} / \mathrm{mL}$ hyaluronidase

$0.2 \mathrm{mg} / \mathrm{mL}$ protease

in $50 \mathrm{~mL}$ RPMI (place in $37^{\circ} \mathrm{C}$ water bath to dissolve)

$4 \quad$ PBS/DNase solution

$0.015 \mathrm{mg} / \mathrm{mL}$ DNase in sterile PBS

5 Percoll solution (isotonic)

$80 \%$ Percoll

$30 \% \mathrm{RPMI} / \mathrm{DNase}$ solution

\section{Prepare tissue fragments and isolate cells}

1. Weigh skin samples (if under $1 \mathrm{~g}$ total tissue wet weight, do not use).

2. Place skin samples in a sterile petri dish and add $25 \mathrm{ml}$ RPMI. Using sterile forceps, tweezers and scissors, cut samples into small pieces $\left(1-2 \mathrm{~cm}^{3}\right.$. It is important to keep the tissue samples wet at all times.

3. Using sterile tweezers carefully place tissue pieces into a $50 \mathrm{ml}$ conical tube and centrifuge at $200 \times g$ for $5 \mathrm{~min}$ at room temperature (RT). Pipette off the medium and resuspend the tissue in $10 \mathrm{ml}$ RPMI. 
4. Centrifuge the tissue at $200 \times \mathrm{g}$ for $5 \mathrm{~min}$ at RT.

5. Remove supernatant and split into as many $1-2 \mathrm{~g}$ samples as necessary. Place each 1-2 sample into a $50 \mathrm{ml}$ conical tube.

6. Add $15 \mathrm{ml}$ of protease solution to each tube of tissue and place tubes on a rotating table at $37^{\circ} \mathrm{C}$ for $1 \mathrm{hr}$.

7. After $1 \mathrm{hr}$, remove supernatant and place in a new conical tube. Place supernatant on ice.

8. Add $15 \mathrm{ml}$ of protease solution to tissue pellet and place back on rotating table at $37^{\circ} \mathrm{C}$ for another $30 \mathrm{~min}$.

9. Remove tissue from rotating table and add $10 \mathrm{~mL}$ of PBS/DNase solution. Place back into rotating table for another $30 \mathrm{~min}$.

10. Remove tissue from oven and filter through a 70 micron cell strainer to remove the large undigested pieces of tissue. Store filtrate on ice.

11. Rinse the tissue in the tube by shaking and swishing in fresh RPMI. Remove supernatant and filter through cell strainer. Discard the rest of the tissue which at this point is mainly adipose tissue and may contain some oil droplets depending upon where the skin tissue was obtained.

12. Add RPMI to the filtrate up to $45 \mathrm{ml}$.

13. Pool all supernatants from steps 8,10 and 11 . The filtrate should not contain large pieces of tissue, but may contain red blood cells. To remove red blood cells proceed to step 14. If the cell suspension does not contain many red blood cells, skip to step 17.

14. Resuspend each cell pellet by gently knocking the side of the tube. While gently mixing the tube by hand, add $3 \mathrm{ml}$ of lysis buffer and incubate for $5 \mathrm{~min}$ at RT.

15. Add $10 \mathrm{ml}$ of RPMI/DNase solution to stop the lysis reaction and gently mix the suspension by hand.

16. Centrifuge supernatants at $200 \times \mathrm{g}$ for $10 \mathrm{~min}$. Resuspend cell pellet in $1 \mathrm{ml}$ of RPMI/DNase media.

17. In a sterile $15 \mathrm{ml}$ conical tube, layer $1 \mathrm{ml}$ of cell suspension onto $5 \mathrm{~mL}$ of Percoll solution and spin at $500 \times g$ for $20 \mathrm{~min}$. After spinning, the dense mast cells will have migrated through the Percoll and pelleted at the bottom of the tube.

18. Gently remove the first interface of the Percoll and discard. Resuspend the cell pellet $10 \mathrm{ml}$ of RPMI and count using a hemocytometer.

19. The viability of the mast cells can be determined by staining with trypan blue and counting on a hemocytometer. Purity can be determined by making a cytospin and staining with toluidine blue.

20. Mast cell yield is highly variably and largely depends upon the type of skin tissue used (breast tissue has more mast cells than adult human skin) and the age of the donor (foreskin tissue from donor less than 2 years old has a greater density of mast cells). From $10 \mathrm{~g}$ of foreskin tissue from a $>2$ year old donor, for example, this procedure can yield approximately $1-3 \times 10^{5}$ cells. Mast cells obtained at the conclusion of this procedure are approximately $10-30 \%$ pure. If greater purity is required, enrichment using a positive selection column or fluorescence activated cells sorting can be used. 
NOTE: Enrichment of mast cells using positive selection or cell sorting will result in decreased yields and viability.

Enrichment of skin mast cells using positive selection-As an alternative to Percoll density centrifugation, skin mast cells can also be enriched by fluorescence activated cell sorting (FACS) using surface expression of Fc\&RI and KIT or positive selection using a column and magnetic beads conjugated to an antibody recognizing FceRI.

\section{Fluorescent Activated Cell Sorting (FACS) using expression of FceRI and KIT}

1. At least $1 \times 10^{5}$ cells should be used per sample. Centrifuge for $5 \mathrm{~min}$ at $200 \times g$ at RT.

2. Resuspend cells with PBS $+0.1 \%$ BSA $\left(4^{\circ} \mathrm{C}\right)$ to a density of $1 \times 10^{6}$ cells $/ \mathrm{ml}$, then add $100 \mu \mathrm{l}$ of the cell suspension per flow tube $(5 \mathrm{ml}$ polystyrene round-bottom tube).

3. Add anti-FceRI-APC (or its isotype control; mouse IgG-APC) or anti-CD117-PE (or its isotype control; mouse $\mathrm{IgG}_{1}-\mathrm{PE}$ ) and incubate for $1 \mathrm{~h}$ at $4{ }^{\circ} \mathrm{C}$ in the dark.

Note: The optimal amount of antibody required is approximately $3-5 \mu \mathrm{g} / / 1 \times 10^{6}$ cells for each antibody, but antibody titration is recommended.

4. Wash off excess antibodies by adding $1 \mathrm{ml}$ PBS $+0.1 \%$ BSA to each tube and centrifuge for $5 \mathrm{~min}$ at $200 \times g$ at $4{ }^{\circ} \mathrm{C}$. Resuspend cell pellet in $100 \mu \mathrm{l}$ of the PBS + $0.1 \%$ bovine serum albumin (BSA) buffer.

5. Sort $\mathrm{Fc} \varepsilon \mathrm{RI}^{+} / \mathrm{CD} 117^{+}$cells using standard sorting procedures. To preserve mast cell viability, ensure that the shear and flow rate of the sorter is low. Each sorter has different thresholds and sensitivities and it will be necessary to optimize the sorting settings.

Note: Cells obtained from FACS are generally not amenable to culture due to poor viability and susceptibility to contamination. However, if mast cells will be used for culture, ensure that the FACS machine is equipped with an aseptic sorting module and that all procedures are performed using sterile materials, including sterile sheath fluid.

\section{Enrichment by positive selection and a magnetic column}

1. At least $1 \times 10^{5}$ cells should be used per sample. Centrifuge for $5 \mathrm{~min}$ at $200 \times g$ at RT.

2. Resuspend cells with PBS $+0.1 \%$ BSA $\left(4^{\circ} \mathrm{C}\right)$ to a density of $1 \times 10^{6}$ cells $/ \mathrm{ml}$. Separate into $600 \mu \mathrm{l}$ aliquots in microcentrifuge tubes.

3. Label cells by adding anti-FceRI-PE antibody to a final concentration of $5 \mu \mathrm{g} / 10^{6}$ cells. Mix well and incubate at $4^{\circ} \mathrm{C}$ for $30 \mathrm{~min}$.

4. Wash off excess antibodies by adding $1 \mathrm{ml}$ PBS $+0.1 \%$ BSA to each tube and centrifuge for $5 \mathrm{~min}$ at $200 \times g$ at $4{ }^{\circ} \mathrm{C}$. Resuspend cell pellet in $80 \mu \mathrm{l}$ of the PBS + $0.1 \%$ bovine serum albumin (BSA) buffer.

5. Add $20 \mu \mathrm{l}$ of anti-PE MicroBeads and mix well. Incubate for $30 \mathrm{~min}$ at $4^{\circ} \mathrm{C}$.

6. Wash cells by adding $1 \mathrm{ml}$ of PBS $+0.1 \%$ BSA to each tube and centrifuge for 5 $\min$ at $200 \times g$ at $4{ }^{\circ} \mathrm{C}$. Aspirate supernatant completely and resuspend in $500 \mu \mathrm{l}$ of $\mathrm{PBS}+0.1 \% \mathrm{BSA}$.

7. Prepare magnetic column and place in magnetic separator according to manufacturer's instructions. 
8. Apply cell suspension onto the column and collect unlabelled cells that pass through the column. Wash column with PBS $+0.1 \%$ BSA and collect effluent. This is the fraction that contains unlabelled, contaminating cells.

9. Remove the column from the separator and place on a suitable collection tube. Immediately flush the column with PBS $+0.1 \%$ BSA and firmly push the plunger into the column.

10. Collect the effluent. This is the fraction that contains the PE-labelled mast cells. Determine purity by toluidine blue staining and viability with trypan blue staining as above.

\section{Basic Protocol 2 \\ Isolation of human lung mast cells}

Like skin mast cells, human lung mast cells bind IgE with high affinity to specific FceRI receptors, but unlike skin mast cells, lung mast cells do not express the C5a receptor (CD88) and are not activated by cationic molecules such as substance P, VIP and compound 48/80. IgE-dependent stimulation by activating tyrosine kinases induces characteristic compound exocytosis resulting in the liberation of the preformed mediators and production of prostaglandin D2 and leukotriene C4. In general, isolation of mast cells from human lung tissue is faster and more straightforward and requires the use of only one digestive enzyme -- collagenase.

Materials-Modified Tyrode's buffer:

$137 \mathrm{mM} \mathrm{NaCl}$

$2.8 \mathrm{mM} \mathrm{KCl}$

$12 \mathrm{mM} \mathrm{NaHCO} 3$

$5.5 \mathrm{mM}$ glucose

$0.4 \mathrm{mM} \mathrm{NaH} 2 \mathrm{PO} 4$

10 mM Hepes, pH7.4

$3.5 \mathrm{mg} / \mathrm{ml} \mathrm{BSA}$

Ammonium chloride solution $\left(\mathrm{NH}_{4} \mathrm{Cl}\right.$; StemCell Technologies)

Tris (Sigma-Aldrich)

HEPES solution (1 M; Invitrogen)

$\mathrm{NaOH}$ solution (10 N; Sigma-Aldrich)

$15 \mathrm{ml}$ conical graduated polypropylene centrifuge tubes (Falcon)

$50 \mathrm{ml}$ conical graduated polypropylene centrifuge tubes (Falcon)

$100 \times 15-m m$ petri dishes (Falcon)

70 micron cell strainer (Falcon)

Bovine Pancreatic Deoxyribonuclease I (Sigma-Aldrich)

Collagenase (Sigma-Aldrich)

Tweezers, scissors, and scalpels, kept in sterile beaker with 70\% ethanol

Percoll® (Sigma-Aldrich) 
Fresh lung tissue stored in sterile PBS at $4^{\circ} \mathrm{C}$ or on ice

Note: Tissue segments that have been stored at $4^{\circ} \mathrm{C}$ longer than $24 \mathrm{hr}$ should not be used. Tissue samples should never be frozen.

Tabletop centrifuge

MACS column and magnet (Miltenyi Biotec)

Anti-PE MicroBeads and wash buffer (Miltenyi Biotec)

Anti-Fc\&RI- APC (eBioscience)

Mouse IgG-APC (eBioscience)

Anti-CD117-PE (BD Pharmingen)

Mouse $\mathrm{IgG}_{1}-\mathrm{PE}$ (BD Pharmingen)

\section{Prepare solutions}

1 Lysis buffer

$1.37 \mathrm{~g} \mathrm{NH} 4 \mathrm{Cl}$

$0.515 \mathrm{~g}$ Tris

$250 \mathrm{~mL}$ ddH2O $\mathrm{pH}$ to 7.2

3 Protease solution

$0.5 \mathrm{mg} / \mathrm{mL}$ collagenase

in $50 \mathrm{~mL}$ Tyrode's buffer

PBS/DNase solution

$0.015 \mathrm{mg} / \mathrm{mL}$ DNase in sterile PBS

6 Percoll solution

$80 \%$ Percoll

$30 \%$ RPMI

Prepare tissue fragments and isolate cells-The procedure for isolating lung mast cells is similar to the procedure for isolating skin mast cells with a few notable exceptions. Tyrode's buffer is used in the initial stages of the isolation. The protease solution used to disperse tissues contains only collagenases and requires shorter incubation times for digestion of connective tissue.

1. Weigh skin samples (if under $5 \mathrm{~g}$ total tissue wet weight, do not use).

2. Place skin samples in a sterile petri dish and add $25 \mathrm{ml}$ Tyrode's buffer. Using sterile forceps, tweezers and scissors, cut samples into small pieces $\left(1-2 \mathrm{~cm}^{3}\right)$. It is important to keep the tissue samples wet at all times.

3. Using sterile tweezers carefully place tissue pieces into a $50 \mathrm{ml}$ conical tube and centrifuge at $200 \times g$ for $5 \mathrm{~min}$ at RT. Pipette off the medium and resuspend the tissue in $10 \mathrm{ml}$ Tyrode's buffer.

4. Centrifuge the tissue at $200 \times g$ for $5 \mathrm{~min}$ at RT.

5. Remove supernatant and split into as many $1-2 \mathrm{~g}$ samples as necessary. Place each 1-2 sample into a $50 \mathrm{ml}$ conical tube. 
6. Add $15 \mathrm{ml}$ of protease solution to each tube of tissue and place tubes on a rotating table at $37^{\circ} \mathrm{C}$ for $15 \mathrm{~min}$.

7. After $15 \mathrm{~min}$, remove supernatant and place in a new conical tube. Place supernatant on ice.

8. Add $15 \mathrm{ml}$ of protease solution to tissue pellet and place back on rotating table at $37^{\circ} \mathrm{C}$ for another $30 \mathrm{~min}$.

9. Remove tissue from rotating table and add $10 \mathrm{~mL}$ of PBS/DNase solution. Place back into rotating table for another $30 \mathrm{~min}$.

10. Remove tissue from oven and filter through a 70 micron cell strainer to remove the large undigested pieces of tissue. Store filtrate on ice.

11. Rinse the tissue in the tube by shaking and swishing in fresh Tyrode's buffer. Remove supernatant and filter through cell strainer.

12. Add Tyrode's buffer to the filtrate up to $45 \mathrm{ml}$.

13. Pool all supernatants from steps 8,10 and 11 . The filtrate should not contain large pieces of tissue, but may contain red blood cells. To remove red blood cells proceed to step 14. If the cell suspension does not contain many red blood cells, skip to step 17.

14. Resuspend each cell pellet by gently knocking the side of the tube. While gently mixing the tube by hand, add $3 \mathrm{ml}$ of lysis buffer and incubate for $5 \mathrm{~min}$ at RT.

15. Add $10 \mathrm{ml}$ of PBS/DNase solution to stop the lysis reaction and gently mix the suspension by hand.

16. Centrifuge supernatants at $200 \times \mathrm{g}$ for $10 \mathrm{~min}$. Resuspend cell pellet in $1 \mathrm{ml}$ of RPMI/DNase media.

17. In a sterile $15 \mathrm{ml}$ conical tube, layer $1 \mathrm{ml}$ of cell suspension onto $5 \mathrm{~mL}$ of Percoll solution and spin at $200 \times g$ for $20 \mathrm{~min}$. After spinning, the dense mast cells will have migrated through the Percoll and pelleted at the bottom of the tube.

18. Gently remove the first interface of the Percoll and discard. Resuspend the cell pellet $10 \mathrm{ml}$ of RPMI and count using a hemocytometer.

19. The viability of the mast cells can be determined by staining with trypan blue and counting on a hemocytometer. Purity can be determined by making a cytospin and staining with toluidine blue.

Mast cell yield is highly variably and the best yields are obtained from fresh and healthy (non-smokers) lung tissue. From $10 \mathrm{~g}$ of healthy lung tissue, this procedure can yield approximately $1-3 \times 10^{6}$ mast cells. Mast cells obtained at the conclusion of this procedure are approximately $10-30 \%$ pure. If greater purity is required follow the protocols for enrichment using flow cytometry or magnetic column as described above.

\section{Comentary}

\section{Background}

Mast cells develop from progenitor cells that arise from uncommitted hematopoietic stem cells in the bone marrow. These progenitors express the stem cell factor receptor (SCF receptor or Kit) and represent the major survival and differentiation pathway for mast cells. The interactions between mast cells and the tissue in which they differentiate are crucial to their differentiation and maturation. Mast cells are also distributed in the deeper region of the central nervous system, the upper and lower respiratory epithelium, the bronchial lumen, 
the gastrointestinal mucosa and submucosa, bone marrow and skin. In the skin, lungs and gastrointestinal tract, mast cell concentrations approximate 10000 to 20000 cells $/ \mathrm{mm}^{3}$ and are therefore a suitable source of mast cells for research(Mikhail and Miller-Milinska, 1964). Connective tissue cells, including fibroblasts, contribute to differentiation and maturation of mast cells in tissue by releasing SCF, nerve growth factor (NGF), adhesion molecules and other as yet uncharacterized growth factors. Two mast cell subtypes have been described in tissue - the mucosal $\left(\mathrm{MC}_{\mathrm{T}}\right)$ or connective tissue $\left(\mathrm{MC}_{\mathrm{TC}}\right)$ mast cell. These subtypes are based on structural, biochemical and functional differences but it is becoming increasingly clear that connective type cells can be found at mucosal surfaces and vice versa. The terms "connective tissue mast cell" and "mucosal mast cell" were first described in rodent models where mast cells follow a different differentiation pathway dependent largely upon IL-3. However, in the rodent system, the protease content of connective tissue versus mucosal mast cells is different and is a bit more complex. In the human, distinctive features have been used to differentiate these two subsets. The $\mathrm{MC}_{\mathrm{T}}$ mast cell predominantly expresses the protease tryptase and mast cells isolated from mucosal surfaces such as the lung tend to be rich in $\mathrm{MC}_{\mathrm{T}}$. Furthermore, $\mathrm{MC}_{\mathrm{T}}$ are present in elevated numbers in the mucosa of patients suffering from allergic inflammation or parasitic disease(Bischoff, 2009). Structurally, these cells have distinctive scroll granules and are often found in close proximity to $\mathrm{T}$ cells [6]. The $\mathrm{MC}_{\mathrm{TC}}$ mast cells express tryptase, chymase, carboxypeptidase and cathepsin G; and predominate in the gastrointestinal tract as well as the skin, synovium and subcutaneous tissue(Miller and Pemberton, 2002). Patients with fibrotic diseases often show an increase in $\mathrm{MC}_{\mathrm{TC}}$ in the affected tissues whereas patients with allergic disease do not show these types of changes(Reid et al., 2007).

Mast cells generated from precursor CD34+ in vitro or human mast cells lines such as HMC-1 and LAD2 are excellent models of mast cell biology in that they provide large and pure populations of homogenous mast cells(Kirshenbaum, 2000; Kirshenbaum et al., 1999). However, these mast cells are sometimes immature in phenotype (HMC-1) and are grown in conditions that do not adequately model their tissue environment in vivo. As such, it is often necessary to isolate mast cells from human tissue. Mast cells are large $(10-15 \mu \mathrm{m}$ in diameter) and possess numerous densely packed granules(Dvorak et al., 1993). The protocols described in this unit take advantage of mast cell size and density and their expression of FceRI and Kit to generate enriched populations of either $\mathrm{MC}_{\mathrm{T}}$ or $\mathrm{MC}_{\mathrm{TC}}$. The gastrointestinal tract is another rich source of human mast cells and protocols for their isolation have been described(Sellge and Bischoff, 2006).

\section{Troubleshooting}

Isolation of tissue mast cells is variable and challenging and a successful isolation depends largely on the fresh, healthy tissue from younger donors. Loss of cells can occur during Percoll density centrifugation since an incorrectlyconstituted protocol will change the density of the medium and disrupt the ordered sedimentation of the mast cells. If a pellet does not form after centrifugation, make sure that the correct centrifugal force was used and that the Percoll was mixed correctly. If mast cells are cultured after isolation, contamination with fungi and bacteria is often a problem. The sterility of the starting human tissue is often difficult to control, but whenever possible only sterile solutions should be used and all work should be done in a properly functioning biosafety hood. Should contamination occur, immediately bleach and discard all contaminated flasks and scrub and clean all surfaces that have contacted these flasks with $70 \%$ ethanol. 


\section{Anticipated results}

Generally, mast cell isolation from lung is faster and produces higher numbers of mast cells with reasonable purity. However, mast cell yield is highly variably and depends largely on the healthy, age and freshness of the tissue samples used.

From $10 \mathrm{~g}$ of foreskin tissue from a $>2$ year old donor this procedure can yield approximately $1-3 \times 10^{5}$ cells. From $10 \mathrm{~g}$ of healthy lung tissue, this procedure can yield approximately 1-3 $\times 10^{6}$ mast cells. Mast cells isolated from either lung or skin after Percoll centrifugation but prior to flow cytometric enrichment are approximately $10-30 \%$ pure.

\section{Time consideration}

The initial dissociation and enzymatic digestion of human tissue and Percoll centrifugation can take approximately 6-8 hr, depending upon the amount of starting tissue.

Mast cell enrichment by flow cytometry can take 5-6 hr depending on the set-up time for the sorter (which can take 2-3 hr to flush the system for aseptic sorting) and the sort speed.

Mast cell enrichment by magnetic column can take approximately 2-3 hr.

\section{Acknowledgments}

Research in the authors' laboratory (MK) has been supported by funding from the National Research Council intramural research program, the Canadian Institutes for Health Research and the PEI Business Development Fund. DM is supported by The Division of Intramural Research, NIAID, NIH.

\section{Literature cited}

Bischoff SC. Physiological and pathophysiological functions of intestinal mast cells. Semin Immunopathol. 2009; 31:185-205. [PubMed: 19533134]

Church MK, Clough GF. Human skin mast cells: in vitro and in vivo studies. Ann Allergy Asthma Immunol. 1999; 83:471-5. [PubMed: 10582733]

Dvorak AM, Mitsui H, Ishizaka T. Ultrastructural morphology of immature mast cells in sequential suspension cultures of human cord blood cells supplemented with c-kit ligand; distinction from mature basophilic leukocytes undergoing secretion in the same cultures. J Leukoc Biol. 1993; 54:465-485. [PubMed: 7693841]

Kirshenbaum A. Regulation of mast cell number and function. Hematol Oncol Clin North Am. 2000; 14:497-516. v. [PubMed: 10909037]

Kirshenbaum AS, Goff JP, Semere T, Foster B, Scott LM, Metcalfe DD. Demonstration that human mast cells arise from a progenitor cell population that is CD34(+), c-kit(+), and expresses aminopeptidase N (CD13). Blood. 1999; 94:2333-2342. [PubMed: 10498605]

Mikhail GR, Miller-Milinska A. Mast cell population in human skin. J Invest Dermatol. 1964; 43:249_ 54. [PubMed: 14220232]

Miller HR, Pemberton AD. Tissue-specific expression of mast cell granule serine proteinases and their role in inflammation in the lung and gut. Immunology. 2002; 105:375-90. [PubMed: 11985658]

Nilsson G, Blom T, Kusche-Gullberg M, Kjellen L, Butterfield JH, Sundstrom C, Nilsson K, Hellman L. Phenotypic characterization of the human mast cell line HMC-1. Scand J Immunol. 1994; 39:489-498. [PubMed: 8191224]

Okayama Y, Benyon RC, Rees PH, Lowman MA, Hillier K, Church MK. Inhibition profiles of sodium cromoglycate and nedocromil sodium on mediator release from mast cells of human skin, lung, tonsil, adenoid and intestine. Clin Exp Allergy. 1992; 22:401-409. [PubMed: 1375128]

Reid AC, Silver RB, Levi R. Renin: at the heart of the mast cell. Immunol Rev. 2007; 217:123-40. [PubMed: 17498056]

Sellge G, Bischoff SC. Isolation, culture, and characterization of intestinal mast cells. Methods Mol Biol. 2006; 315:123-38. [PubMed: 16110154] 